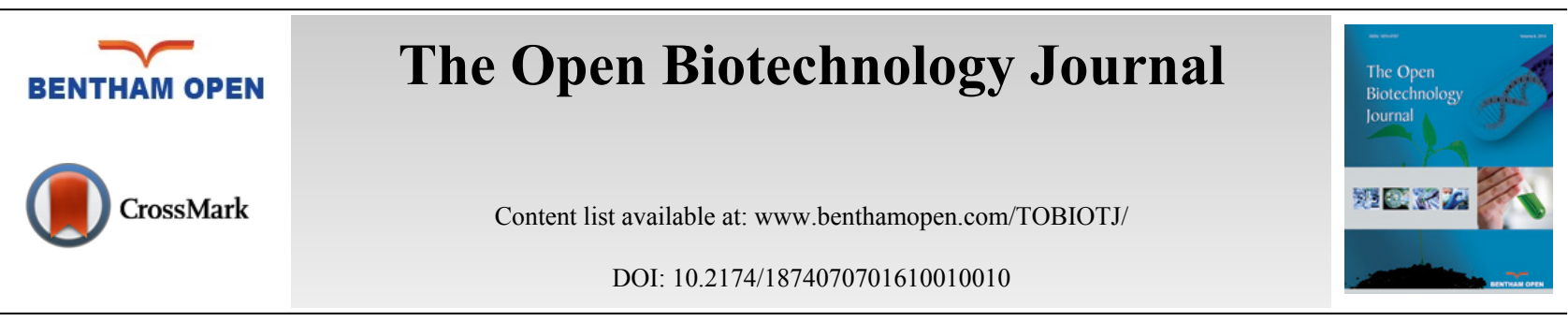

\title{
Editorial
}

\section{Editorial: Environment and Health: The Problem of the Endocrine Disruptors}

Since the publication of the book by Colborn et al. [1] the research on Endocrine Disruptors Chemicals (EDCs) increased along with the concerns for their adverse effects on wildlife, humans and ecosystems. An Endocrine Disruptor was defined by the U.S. Environmental Protection Agency as "an exogenous agent that interferes with synthesis, secretion, transport, metabolism, binding action, or elimination of natural hormones that are present in the body and are responsible for homeostasis, reproduction, and developmental processes". According to this definition it is possible to discriminate toxic effects from endocrine effects: some chemicals can be toxic without producing hormonal effects and, viceversa, not necessarily estrogenic chemicals produce toxic effects. Humans are exposed to endocrine disruptors through the food and beverages they consume, medicines they take, pesticides they apply, cosmetics they use and the air they breathe. Health concerns related to EDCs include infertility, birth defects of male or female reproductive tract, hormone-related cancers (such as breast, testicule and prostate cancer), impaired brain development, cardiovascular diseases, and some metabolic dysfunctions including obesity and diabetes. World Health Statistics 2014 Report by World Health Organization (WHO) alerted us about the decreasing number of adolescent fertility and the worldwide decline in biodiversity of wildlife species. It is plausible that exposure to EDCs is playing a role in this. The group of molecules identified as Endocrine Disruptors is highly heterogeneous and includes polychlorinated biphenyls (PCBs), polybrominated biphenyls (PBBs), dioxins, plastics [bisphenol A (BPA)], plasticizers (phthalates), pesticides [methoxychlor, DDT], fungicides (vinclozolin), and pharmaceutical agents [diethylstilbestrol (DES)]. To date there are nearly 1,000 chemicals reported as endocrine disruptors or suspected endocrine disruptors in the TEDX List [2]. TEDX (The Endocrine Disruption Exchange, Inc.) is an organization, founded by Theo Colborn, that focuses primarily on environmental problems related to the human health. Rates of endocrine diseases have been found to increase proportionally to the growth of the chemical industry, so supporting that these two factors are linked.

Extensive laboratory studies on animal models and epidemiological data on humans have shown that the interference with hormone action during critical periods of development can cause irreversible and delayed effects later in life. Indeed, exposure of an adult to an EDC may have very different consequences from the same exposure of a developing fetus or infant, according to the hypothesis of "the fetal basis of adult disease". This circumstance indicates that the environment of a developing organism, i.e. the maternal environment for mammalians, the egg for vertebrates and, in general, the external environment, interacts with the offspring's genes determining the propensity of that individual to develop later in life a disease or a dysfunction. At this point, drawing the appropriate conclusions, it would be possible to affirm that there are no doubts about the harmful effects induced in wildlife and in humans by Endocrine Disruptors. This statement is supported by what published by the WHO and the International Programme on Chemical Safety (IPCS) in "The Global Assessment of the State-of-the-Science of Endocrine Disruptors" [3]. In the subsequent years the research on EDCs increased so that the WHO with the United Nations Environment Programme (UNEP) updated the 2002 report publishing on 2012 into the book "State of the Science of Endocrine Disrupting Chemicals - 2012 [4]. All these authoritative publications, however, are not unanimously accepted and a very small part of the scientific community [5 - 7], also presenting valid reasons, disputes the conclusions of the reports above mentioned. The conclusions, however, become more complicate considering that in the environment more classes of EDCs are simultaneous present and, therefore, one must take in account their additive or synergistic effects. The debate continues to grow and no definitive answers have yet been reached. In this monothematic issue we don't have the presumption to claim that it possesses the truth, but simply to witness what some scientists have found in the course of their research 
activity. Some of the problems and subject matters related to the EDCs are illustrated in the manuscripts collected in this monothematic issue. A very general speech to focus the problem is in the paper "Endocrine Disruptors: a real concern for humans?" (by Mita), while a detailed overview is presented in the paper "Endocrine Disruption in the Omics Era: New Views, New Hazards, New Approaches" by Piña. The paper "Epigenetic reprogramming in the mammalian germ line: possible effects by endocrine disruptors on primordial germ cells" by De Felici describes the possible effects induced by EDCs on primordial germ cells. Subsequent manuscripts face the problem of tumors induced by EDCs with particular reference either to the gender "Gender and age related modulation of xenoestrogeninduced tumorigenesis" by Fucic or specific in men as that one dealing with "Actions of Estrogenic Endocrine Disrupting Chemicals on Human Prostate Stem/Progenitor Cells and Prostate Carcinogenesis" by Hu. The problem of the effects on the female reproductive system is well described in the manuscript "Effects of endocrine-disrupting chemicals on female reproductive health" by Zama. The role of food and the associated dysfunctions are discussed in the trilogy of manuscripts authored by Mantovani "Endocrine Disrupters and Food Safety" , by Calhau "The role of endocrine disruptors on metabolic dysfunction" and by Diano "Adverse effects of Bisphenol A exposure on glucose metabolism regulation". With regard to marine pollution by EDCs Maha presents a case study: Endocrine disruptors as pollutants in Marine Ecosystem: A case study in Egypt. To finish and with reference to cleaning up of aqueous systems polluted by EDCs three different biotechnological processes are presented and discussed: "Removal of endocrine disruptors from urban wastewater by advanced oxidation processes (AOPs): a review" by Belgiorno; "Phytodecontamination of Water Systems from Phenolic Endocrine Disruptors and the Regulation Role of Natural Organic Matter" written by Loffredo, and "Bioremediation of waters polluted by Endocrine Disruptors by means of the process of thermodialysis" authored by Mita.

To conclude it is possible to affirm that a better understanding of the role of exposure to environmental pollutants in the risk of endocrine diseases in both humans and wildlife is necessary to protect ourselves and wildlife from any harm caused by these chemicals. Work that still needs to be done includes: i) to identify new compounds acting as endocrine disruptors and to develop reliable and sensitive determination methods; ii) to understand the impact on the development of endocrine diseases of age, dose, duration of exposure, timing of exposure; iii) to investigate the genetics and epigenetics effects associated to the EDCs exposure; iv) to examine the interactions between multiple synthetic chemicals and how they react in the body and into the environment; v) to decrease the presence of endocrine disruptors by improving the strategies for wastewaters treatment.

\section{CONFLICT OF INTEREST}

The author confirms that this article content has no conflict of interest.

\section{ACKNOWLEDGEMENTS}

Declared none.

\section{REFERENCES}

[1] Colborn T, Dumanoski D, Myers JP. Our stolen future. New York: Dutton 1996.

[2] TEDX list. Available from: http://endocrinedisruption.org/endocrine-disruption/tedx-list-of-potential-endocrine-disruptors/overview

[3] WHO-IPCS. Global Assessment of the State of the science of Endocrine Disruptors 2002. Available from: http://www.who.int/ipcs/ publications/new_issues/endocrine_disruptors/en/

[4] Bergman A, Heindel JJ, Jobling S, Kidd KA, Zoeller RT, Eds. WHO-UNEP. State of the Science of Endocrine Disrupting Chemicals. IOMC 2012. Available from: http://www.who.int/ceh/ publications/endocrine/en/index.html

[5] Rhomberg LR, Goodman JE, Foster WG, Borgert CJ, Van Der Kraak G. A critique of the European Commission document, "State of the art assessment of endocrine disrupters. Crit Rev Toxicol 2012; 42(6): 465-73. [http://dx.doi.org/10.3109/10408444.2012.690367] [PMID: 22630047]

[6] Lamb JC IV, Boffetta P, Foster WG, et al. Critical comments on the WHO-UNEP State of the Science of Endocrine Disrupting Chemicals 2012. Regul Toxicol Pharmacol 2014; 69(1): 22-40. [http://dx.doi.org/10.1016/j.yrtph.2014.02.002] [PMID: 24530840]

[7] Kortenkamp A, Martin O, Evans R, et al. Response to A critique of the European Commission Document, "State of the art assessment of endocrinedisrupters" by Rhomberg and colleagues - letter to the editor. Crit Rev Toxicol 2012; 42(9): 787-9. [http://dx.doi.org/10.3109/10408444.2012.712943] [PMID: 22900988] 
Damiano G. Mita

National Laboratory on Endocrine Disruptors of INBB

Via Pietro Castellino 80131

Naples

Italy

Email:mita@igb.cnr.it

(C) Damiano G. Mita; Licensee Bentham Open.

This is an open access article licensed under the terms of the Creative Commons Attribution-Non-Commercial 4.0 International Public License (CC BY-NC 4.0) (https://creativecommons.org/licenses/by-nc/4.0/legalcode), which permits unrestricted, non-commercial use, distribution and reproduction in any medium, provided the work is properly cited. 